\title{
REFORMA NO SETOR DE SEGURANÇA EM ESTADOS PÓS- AUTORITÁRIOS AFRICANOS: CONCLUSÕES PRELIMINARES A PARTIR DOS CASOS NIGERIANO E TUNISIANO.
}

\section{Security Sector Reforms in Post-Authoritarian African States: preliminary conclusions from the Nigerian and Tunisian cases}

Carlos Schmidt Arturi ${ }^{1}$ Guilherme Ziebell de Oliveira ${ }^{2}$

Mariana Falcão Chaise ${ }^{3}$

\section{Introdução}

O presente artigo examina dois processos independentes e estruturalmente relacionados de reformas no setor de segurança pública, composto - para fins analíticos - pelas Forças Armadas, Polícias e Serviços de Inteligência. Os países que servirão de estudos de caso passam, ambos, por processos de transição política - com maior ou menor celeridade - a partir de regimes autoritários. A Tunísia, hoje pretendente a um modelo de democratização a ser seguido pelos demais países árabes e magrebinos, iniciou sua transição com a Revolução de Jasmim de janeiro de 2011 (estopim para a chamada "Primavera Árabe”). Zine El Abidine Ben Ali, presidente durante vinte e quatro anos, caiu em apenas dez dias. A Nigéria, em um processo bastante mais lento, iniciou seus esforços por reformas liberalizantes após 1999, com a eleição de Olusegun Obasanjo, que inaugurou a Quarta República de um país com pouco mais de 50 anos de pósindependência.

O conceito de Reforma no Setor de Segurança (RSS) que utilizaremos emergiu em 1999, depois de empregado em um discurso pela Secretária de Estado para o Desenvolvimento Internacional da Inglaterra, Clare Short. ${ }^{4}$ Tal conceito, relativamente ambíguo, normativo, mas bastante ambicioso, diz respeito à

\footnotetext{
${ }^{1}$ Professor Titular do Departamento de Ciência Política da Universidade Federal do Rio Grande do Sul (UFRGS). Doutor em Ciência Política pelo Institut d'Etudes Politiques de Paris - Sciences Po (1999) e Pós-Doutor pela Universidade de Lisboa (2005). Email: 00005757@ufrgs.br

${ }^{2}$ Doutorando do Programa de Pós-Graduação em Ciência Política da Universidade Federal do Rio Grande do Sul (PPGPol/UFRGS). Mestre em Estudos Estratégicos Internacionais pelo PPGEEI/UFRGS. Graduado em Relações Internacionais pela UFRGS. Email: guilherme.ziebell@ufrgs.br

${ }^{3}$ Mestra em Ciência Política pelo Programa de Pós-Graduação em Ciência Política da Universidade Federal do Rio Grande do Sul. Bacharela em Relações Internacionais pela mesma Universidade. Email: marichaise@gmail.com

${ }^{4}$ Discurso proferido em 9 de março de 1999, em Londres, no Centre for Defence Studies, King’s College. Na ocasião, a secretária Short sublinhou a ineficácia de estratégias anteriores de desenvolvimento. Para ela, um setor de segurança de tamanho apropriado, bem administrado, que preste contas às autoridades civis, em um quadro democrático, é chave para o sucesso de políticas para países
} 
reforma das instituições do setor público encarregados da provisão de segurança interna e externa, em um contexto de pretendida governança democrática. Assim, Reforma no Setor de Segurança inova ao nos propor uma abordagem holística, na qual paz e segurança são vistos como bens públicos, de modo que seu objetivo é reduzir não apenas déficits em segurança, resultantes da ineficiência e da ineficácia na ação setor, mas possíveis déficits no modelo de governança democrática, caso o setor careça de fiscalização e de transparência e caso atue não em função do bem-estar da população, mas em proveito próprio ou do regime. De tal maneira, Reforma no Setor de Segurança integra diversas reformas parciais, nas Forças Armadas, nas Polícias, nos órgãos de controle, sendo uma pré-condição a apropriação nacional dos projetos. Ainda que doadores externos ${ }^{5}$ sejam atores importantes, seu engajamento direto é raro, sua ação - por vezes - se mostra inadequadamente ambiciosa e suas avaliações, imprecisas acerca das realidades políticas dos parceiros (HÄNGGI, 2004; HILL, 2010; WULF, 2004). ${ }^{6}$

No âmbito acadêmico, Reforma no Setor de Segurança se desenvolveu como uma reação às limitações da linha tradicional de estudos em Relações Civil-Militares, seus conceitos e suas agendas. Em primeiro lugar, porque deixou de considerar apenas as Forças Armadas como provedoras de segurança, propondo um conceito mais amplo de "setor" ou de "comunidade de segurança”. Em segundo lugar, buscou considerar os papeis e as missões dos componentes do setor, e sua natureza intercambiável: militares agindo como polícia e polícia agindo para fins de contraterrorismo. Em terceiro lugar, enfatizou a já mencionada noção de governança, abandonando uma agenda anterior interessada unicamente em controle civil democrático. Ainda, RSS tem por mérito o de migrar do foco da realidade ocidental e estadunidense para as realidades de países pobres e em desenvolvimento (BRUNEAU, MATEI, 2008).

Conquanto o modelo de Reforma no Setor de Segurança varie segundo o contexto específico e ainda que - na prática - cada país constitua um caso especial de estudo, podem ser mencionados três tipos de reforma, para fins analíticos. Em primeiro lugar, existe Reforma no Setor de Segurança para contextos de desenvolvimento, tal qual o aplicado para Serra Leoa e Libéria; também, para contexto de pós-conflito, como nos casos do Iraque e do Afeganistão; por fim, para contextos pós-autoritários, dois dos quais serão analisados neste artigo (HÄNGGI, 2004). Considerando este último, muito se escreve acerca da transição para a democracia, mas muito pouco sobre o autoritarismo enquanto um sistema político, com características e processos próprios, ou mesmo sobre a consolidação democrática. Militares em Estados autoritários, por exemplo, possuem um caráter dúbio, pois ao mesmo tempo em que reprimem a dissidência política, garantindo a manutenção do regime, estão em uma posição privilegiada para fazer demandas, agindo, portanto, como um importante grupo de pressão (CROISSANT; KUEHN, 2015; DUVERGER, 1967). Além dos militares, regimes autoritários estabelecem intrincadas redes de organizações de segurança com

pobres e em desenvolvimento. Um dos principais obstáculos para a redução da pobreza e para o desenvolvimento seria a existência de setores de segurança violentos, repressores, não democráticos e secretos (SHORT, 1999).

${ }^{5}$ Os doadores externos são terceiros países, não inseridos no contexto imediato da RSS, que fornecem recursos para promover as reformas, estabelecendo critérios próprios para a concessão dos recursos. Em geral, trata-se de países desenvolvidos, com grande destaque para os Estados Unidos.

${ }^{6} \mathrm{Em}$ 2001, a Organização para a Cooperação e Desenvolvimento Econômico (OCDE) lançou, em 2001, um quadro conceitual para Reforma no Setor de Segurança, com seis amplas recomendações para os membros do seu Comitê de Ajuda ao Desenvolvimento (CAD). Em 2008, lançou um Handbook com o objetivo de garantir a eficiência e a sustentabilidade do suporte externo. Esses materiais servem de referência básica no estudo de Reforma no Setor de Segurança. 
diferentes missões oficiais, mas com objetivos redundantes. Após as mudanças de regime, parte dessa infraestrutura permanece existindo, se mostrando, portanto, surpreendentemente resistente à mudança (PERITO, 2015; QUINLIVAN, 1999).

Nos países recentemente democratizados, seus atuais órgãos de inteligência e de segurança interna são, frequentemente, herdeiros ou meras continuações daqueles que operavam durante as ditaduras, formados estreitamente vinculados aos imperativos da repressão política e das contingências da Guerra Fria; ao contrário, nas democracias mais tradicionais, seus serviços de inteligência e de segurança pública desenvolveram-se primordialmente sob a forte influência da diplomacia e da guerra (Cepik, 2003). Assim, o amálgama entre segurança pública e segurança nacional, bem como entre inimigo externo e interno, impregnou os passos iniciais da institucionalização dos serviços de inteligência e de manutenção da ordem interna na maioria dos países recentemente democratizados, muitas vezes com efeitos deletérios para as liberdades civis.

A comparação entre os casos tunisiano e nigeriano permitirá melhor qualificar algumas hipóteses que relacionam o tipo de regime anterior e o modo de transição como variáveis explicativas para os constrangimentos à consolidação dos novos regimes democráticos, particularmente, aqueles dilemas que se referem à institucionalização dos serviços de inteligência e de segurança pública, com legitimidade e sob controle democrático.

A questão que buscamos responder, portanto, é em que medida os atuais regimes da Tunísia e da Nigéria tentam resolver estes dilemas e tensões entre segurança e liberdade? Como estão constituídos e atuam seus sistemas de inteligência e de segurança interna? Qual o padrão estabelecido das relações entre civis e militares? Qual o grau de controle político democrático sobre as organizações de inteligência e de segurança? Os limites, atribuições, os mandatos legais e a coordenação destes órgãos estão claramente definidos?

Nossa principal hipótese é a de que as principais variáveis explicativas da configuração e evolução recente dos sistemas de inteligência e de segurança nos dois países são: as características das ditaduras, o modo de transição política, o desenho institucional inicial destes órgãos, a interação entre os diversos atores envolvidos, especialmente as elites políticas, e suas escolhas estratégicas, bem como as relações entre civis e militares. Além destas variáveis propriamente domésticas, exercem influência no tema variáveis externas como a conjuntura política regional, ameaças transnacionais (terrorismo, etc.) e pressões de outros países e de órgãos multilaterais variados. Essas variáveis possuem pesos diferenciados e incidem diferentemente na configuração do setor de segurança, conforme a história política de cada país.

De tal maneira, os esforços deste artigo se concentrarão em duas frentes. Os processos de RSS serão analisados naquilo que se refere (i) aos contextos imediatamente anteriores à proposição das reformas, buscando identificar os principais atores políticos; (ii) às políticas de reforma propostas; (iii) aos resultados observáveis; (iv) aos atores externos (doadores) envolvidos. Concomitantemente, deve-se analisar o ambiente securitário no momento de proposição e de implementação. 
O que pôde ser observado ao longo da pesquisa empreendida foi, primeiramente, a resistência à mudança apresentada por algumas organizações de segurança, mesmo após a queda dos regimes por elas sustentados, pois seus quadros encontravam-se entre as camadas mais privilegiadas destas sociedades. ${ }^{7}$ Também, o sucesso das reformas se mostrou especialmente desafiador, uma vez que sua implementação se deu concomitantemente à escalada de ameaças securitárias.

A título de justificativa para este trabalho, observa-se uma literatura ainda escassa relativa à consolidação democrática e às relações civil-militares em países não ocidentais. Ademais, os estudos existentes dão pouca atenção às forças policiais destes países e a seus serviços de inteligência, ainda que estes desempenhem papel fundamental na manutenção dos regimes autoritários e estejam sujeitos a denúncias diversas de perseguição política, tortura, intimidação (BRUNEAU; MATEI, 2008; FERGUSON; ISIMA, 2004). Sobre a escolha dos casos, uma vez que o conceito de Reforma no Setor de Segurança emergiu nos anos 1990, a delimitação de nosso universo de possibilidades se deu a partir desse período. Os poucos estudos de caso que têm por objetivo analisar o contexto pós-autoritário apontado versam, em sua maior parte, sobre os Estados pós-comunistas da Europa Central e Oriental e Estados pós-Soviéticos. Estudos sobre a África Subsaariana e sobre o Norte Africano permanecem raros.

\section{Tunísia: transição incompleta e o imperativo de reforma no setor de segurança para o ministério do} interior

O cenário político tunisiano mostra-se mais complexo do que o pretendido por alguns analistas, que apresentam a Tunísia como um modelo de transição política a ser seguido por seus pares, no contexto da chamada "Primavera Árabe". ${ }^{8}$ Apesar de o país ter sido bem sucedido na realização de eleições nacionais, amplamente avaliadas como livres e justas, e apesar de não ter havido rupturas no processo pósrevolucionário, ${ }^{9}$ um dos legados do regime de Ben Ali se mantem firme, na medida em que o setor de segurança interna resiste às subsequentes tentativas de reestruturação.

Ao contrário de países vizinhos, a Tunísia não teve a experiência da guerra de libertação. Conquistou sua independência por meio de acordos entre a colônia francesa e o partido nacionalista, o NeoDestour, fomentados pela ameaça de um movimento nacionalista alternativo, de inspiração nasserista. A crise política que opunha dois líderes, Habib Bourguiba, inspirado pelo liberalismo e pela ideia de desenvolvimento associado ao Ocidente, e Salah Ben Youssef, cujo discurso nacionalista impregnado de referências ao Islã propunha um desenvolvimento autônomo, constituiu a matriz do regime autoritário de Bourguiba a partir da criação de uma visão orgânica de nação, que recusava o conflito, assimilado à sedição.

\footnotetext{
${ }^{7}$ Segundo Bendix e Stanley (2008), a própria natureza do Estado e das instituições africanas - das Forças Armadas em particular enquanto heranças do colonialismo são fonte de insegurança. As elites políticas de muitos dos países da África replicam a abordagem instrumental de seus antecessores coloniais em relação ao poder estatal, de modo que as forças de segurança continuam a servir aos interesses destas elites, visando à manutenção de seus domínios.

${ }^{8}$ Stepan (2012), por exemplo, após ter estudado esforços de democratização no Brasil, no Chile, na Índia, no Senegal, propõe que - em 2011 - a Tunísia teria atingido uma transição democrática de sucesso; no entanto, não ainda uma verdadeira consolidação desta democracia.

${ }^{9}$ No Egito, logo após as manifestações da Primavera Árabe, o primeiro civil eleito presidente, Mohamed Morsi, um dos líderes da Irmandade Muçulmana, foi removido do cargo pelo Conselho Supremo das Forças Armadas (SCAF). Atualmente, o General Abdel Fattah el-Sisi governa o país.
} 
O Novo Estado tunisiano, arquétipo do Estado reformador árabe contemporâneo, aumentou ao máximo seu controle sobre os indivíduos e grupos, a fim de neutralizar os particularismos e secularizar a vida social e política, de modo que todas as instituições fossem submetidas ao controle direto do Estado-partido. Habib Bourguiba foi presidente da Tunísia e secretário-geral do partido de 1957 a 1987. Seu sucessor, Zine el Abidine Ben Ali, antigo ministro do interior, manteve os pilares do regime de seu antecessor: a onipotência do presidente, o partido hegemônico ${ }^{10}$ e o controle policial da sociedade. A Tunísia sob Ben Ali era considerada um Estado policial por excelência, no qual o presidente - sensivelmente menos carismático que o anterior - se apoiava no aparato de segurança interno a fim de garantir a manutenção do regime (CHOUIKHA, GOBE, 2015; LUTTERBECK, 2013; CAMAU, 1989).

A Revolução de Jasmim, de janeiro de 2011, foi fruto da deterioração da economia nacional, especialmente expressa no alto nível de desemprego, e da corrupção na cúpula do governo. Dez dias após o seu início, Ben Ali teve que fugir com sua família para a Arábia Saudita, criando um vazio de poder que seria preenchido em outubro, quando o partido islamista moderado Ennahda, de mesma matriz dos Irmãos Muçulmanos egípcios, ${ }^{11}$ conquistou $40 \%$ dos assentos legislativos.

A elite tunisiana é desproporcionalmente oriunda do Sahel, região oeste da Tunísia, de onde provinha Bourguiba. Uma característica importante é que a estrutura governamental e a liderança partidária estão praticamente sobrepostas. Assim, virtualmente todos os membros ativos da elite exercem sua influência através das estruturas políticas, e não de instituições alternativas como as militares, as organizações econômicas e os órgãos culturais (STONE, 1982). Especificamente sobre os militares, ao contrário de homólogos em outros países árabes - e possivelmente devido ao processo de formação do Estado - o Exército tunisiano nunca teve um papel político relevante, nem servia para a legitimação do regime. Bourguiba tinha consciência da ameaça à autoridade civil imposta por militares fortes em países árabes, de modo que manteve seus efetivos e seu orçamento reduzidos. ${ }^{12}$ Ele não envolvia líderes militares no partido ou na administração pública, nem os militares recebiam compensações materiais e sociais pelos seus serviços ao Estado, tal qual no Egito e na Argélia. O status dos militares não se alterou quando Ben Ali assumiu a presidência; sua força política e repressiva não estava no Exército, mas na segurança interna, dirigida pelo Ministério do Interior. Assim, em termos de Reformas no Setor de Segurança em países pósautoritários, as Forças Armadas tunisianas não serão relevantes (JEBNOUN, 2014a; ALEXANDER, 2014, HANLON, 2012).

\footnotetext{
${ }^{10}$ O Néo-Destour foi rebatizado, em 1964, Parti Socialiste Destourien (PSD). Em 1988, Ben Ali novamente altera o nome do partido para Rassemblement Constitutionnel Démocratique (RCD).

${ }^{11}$ A oposição islamista surge, na Tunísia, nos anos 1970, com a Jamâ’a al-islamiyya. Como no resto do mundo árabe, o islã político nasceu do esgotamento do projeto nacional modernizador e da derrota árabe em 1967, sendo os Irmãos Muçulmanos um precursor. Nos anos 70, o poder estatal não se mostrou necessariamente hostil ao islã político e viu neles um polo de resistência contra a juventude de extrema esquerda tunisiana. Em 1979, a Jamâ'a al-islamiyya se transforma em Mouvement de la tendance islamique. Em 1989, se transforma em Mouvement Ennahda. O movimento salafista jihadista que começara a se instalar nos anos 1990 e será representado, nos anos 2010 pela Ansar al-Sharia (mais assemelhada ao Front Islamique du Salu - FIS - argelino) é bastante mais rigoroso, reivindicando especialmente a fusão do civil com o religioso, a estrita aplicação da lei islâmica, a separação entre os sexos em espaço público e a interdição do álcool (AYARI, MERONE, 2014; CHOUIKHA, GOBE, 2015).

${ }^{12}$ Segundo o Military Balance de 2010 e de 2014, produzido pelo International Institute of Strategic Studies, o Exército tunisiano possui um efetivo de 27.000, a Força Aérea, 4.000 e a Marinha, 4.800 pessoas.
} 
As Forças de Segurança Interna - por outro lado - incluíam, em 2011, a Polícia Nacional, a Guarda Nacional, a Proteção Civil e os agentes prisionais (TUNÍSIA, 1982). Ainda sob o Ministério do Interior encontravam-se a Guarda Presidencial e os serviços de inteligência: a Direction de la Surête nationale, de cujas agências, a Direction de la sûreté de l'État era aquela identificada como "polícia política", encarregada de vigiar e de reprimir opositores. ${ }^{13}$ Os serviços de segurança interna nunca estiveram sob escrutínio legislativo, controle judiciário ou fiscalização por parte da sociedade civil, operando fora de qualquer enquadramento legal (JEBNOUN, 2014b; HANLON, 2012). Em 2011, os manifestantes demonstraram sua indignação com a repressão e com a violência praticadas por essas instituições ao queimarem delegacias de polícia. Dados do Afrobarômetro para a rodada 2011/2013 demostram que ao passo que 57,3\% dos tunisianos afirmavam confiar muito no Exército, apenas 17\% afirmavam confiar no mesmo nível na Polícia.

Logo após a fuga de Ben Ali, no cenário anterior às eleições de outubro de 2011, algumas mudanças foram promovidas no âmbito do Ministério do Interior. Em fevereiro deste mesmo ano, o então ministro interino do interior, Farhat Rajhi, ${ }^{14}$ sob pressão de associações de direitos humanos, destituiu 42 servidores do Ministério do Interior, incluindo 11 diretores de agências de segurança e 26 membros da Direction de la Surête nacionale. Essa decisão, no entanto, foi tomada fora de qualquer arcabouço de justiça transacional, causando grande confusão no nível operacional destas estruturas. No mês seguinte, Rajhi desmantelou a notória Direction de la Sûreté de l'État, criando novamente um vácuo estrutural, sem - no entanto - propor reformas profundas para o Ministério, ou mesmo nova regulação para o setor de inteligência (SAYIGHO, 2015; MAHFOUDH, 2014).

A formação de sindicatos independentes para o setor de segurança, a partir de maio de 2011, no entanto, afetou as relações entre o pessoal de segurança e o Ministério do Interior, permitindo o contato com partidos políticos, com a mídia, bem como a aglutinação de interesses para proposição de agendas. Um indicador de que a reforma no Ministério do Interior era uma prioridade do governo de transição foi a preparação, a partir de julho, de um Livro Branco com propostas de Reformas no Setor de Segurança, envolvendo reformas na Polícia Nacional e na Inteligência, a necessidade de transparência do Ministério e o fim das prisões motivadas por ideologias políticas e religiosas (MAHFOUDH, 2014; HANLON, 2012). Uma ação final de grande impacto foi o estabelecimento de uma comissão eleitoral independente para supervisionar as eleições de 2011. Até então, a legislação previa que o Ministério do Interior era "responsável pela organização e pelo bom desenrolar das eleições, bem como pela proclamação dos resultados" (TUNÍSIA, 1975, p.1). ${ }^{15}$ A nova comissão foi uma condição chave para um processo eleitoral justo, livre e transparente.

Nas eleições de outubro de 2011, o partido islamista Ennahda conquistou 89 de 217 assentos na Assembleia Nacional, que deveria preparar a nova constituição. O segundo e o terceiro partidos mais

\footnotetext{
${ }^{13}$ Para as atividades de vigilância, outros agentes do regime trabalhavam na coleta de informações - células do RCD, escritórios informais. O Ministério do Interior, entretanto, teve papel preponderante no final da corrente, recolhendo e analisando o conjunto de informações (PATCHON, 2014).

${ }^{14}$ Esteve no cargo de 27 de janeiro a 28 de março de 2011.

${ }^{15}$ No original: Le Ministère de l'intérieur est responsable de l'organisation et du bon déroulement des opérations électorales ainsi que de la proclamation de leurs résultats.
} 
votados - o Congrès pour la République (CPR) e o Forum Démocratique pour le Ttravail et les Libertés (FDTL, ou Ettakatol) -, ambos seculares, se juntaram ao Ennahda em uma coligação, que optou por Moncef Marzouki, do CPR, como presidente interino e Hamadi Jebali, do Ennhda, como Primeiro Ministro. Logo no início dos debates na Assembleia Constituinte, no entanto, o papel da religião na vida pública gerou tensões entre partidos e militantes dos campos islamista e secular. Novamente, organizações da sociedade civil voltaram a criticar o governo, expondo a tradicional clivagem entre um país conservador, que votou maciçamente nos islamistas, e um país que reivindicava a herança modernista tunisiana (ALEXANDER, 2014).

A nova polarização entre islamistas e secularistas e a escalada de violência jihadista no país desaceleraram os ímpetos de Reforma no Setor de Segurança. Alguns analistas - inclusive - alegam que apesar dos avanços, a gestão das Forças de Segurança Interna se manteve pior que na época de Ben Ali; o setor permaneceu extremamente centralizado, regulado pelas mesmas leis anteriores à Revolução de Jasmim, e seus altos escalões seguiram exercendo um poder quase discricionário (ICG, 2015). A desconfiança em relação ao novo ministro do interior, Ali Laraidh, membro do Ennahda, se tornaram patentes quando Laraidh classificou o Livro Branco como um "legado do regime anterior”, arquivando-o. As tentativas do partido islamista de assegurar controle governamental sobre o Ministério do Interior levantaram suspeitas de que o seu real objetivo era partidarizar o aparato securitário, acusações semelhantes às levantadas contra os Irmãos Muçulmanos no Egito, sob o nome de Ikhwanização:16 imposição de doutrinas religiosas às instituições estatais (SAYAGHO, 2015).

Ademais, alguns ataques terroristas de pequena escala iniciaram ainda em 2011. Um dos motivos imediatos foi o decreto assinado pelo então Primeiro Ministro Mohamed Ghannouchi, em fevereiro, seis dias após a fuga de Ben Ali, garantindo anistia geral para prisioneiros políticos condenados pelo ex-presidente. Em março de 2012, um relatório das Nações Unidas constatou que todos os prisioneiros condenados com base da lei antiterrorismo haviam sido libertados (ONU, 2012). Um destes foi Seifallah Ben Hassine, que fundará a organização Ansar al-Sharia. ${ }^{17} \mathrm{O}$ Ennahda não logrou canalizar para si a contestação salafistajihadista em plena ascensão entre os jovens proletários de bairros populares. A Ansar al-Sharia representará esses setores heterogêneos, sendo considerada pelas autoridades a responsável pela maior parte da violência social, juvenil, política e religiosa posterior à queda do regime benalista. No campo secular, cada nova violência era uma oportunidade para demonstrar à classe média que a soberania do Estado, bem como o pluralismo de valores e de modos de vida, estavam em risco, de modo que um retorno ao Estado policial era necessário à saúde do país, com ou sem o apoio do Ennahda (AYARI, MERONE, 2014).

Além da situação interna, diversas células e grupos terroristas - como a Okba ibn Nafaa Battalion e a Al-Qaeda do Magreb Islâmico (AQMI) - começaram a atuar na fronteira com a Argélia. A difícil situação na Líbia também teve reflexos nas fronteiras tunisianas, zona de trânsito para redes regionais de contrabando de armas e para refugiados, alguns partidários de ideologias extremistas. Esse cenário aumentou a pressão

\footnotetext{
${ }^{16}$ O termo provém de Ikhwan, “irmãos” em árabe.

${ }^{17}$ Ansar al-Charia da Tunísia foi criado em abril de 2011 e foi rapidamente sucedida por dois grupos homônimos na Líbia e no Iêmen (BÉCHIR, MERONE, 2014).
} 
sobre as forças de segurança, incluindo os militares. Igualmente, nacionais tunisianos constituem - hoje um dos maiores contingentes de combatentes islamistas na Síria (ARIEFF, HUMUD, 2015; MAHFOUDH, 2014),

Nesse contexto, a janela de oportunidade para o estabelecimento de reformas efetivas no setor de segurança se fechou em meados de 2013, antes da promulgação da constituição. A partir desta data, a violência política escalonou. Dados da Tunisian Institutional Reform, uma organização nacional responsável pelo apoio à transparência institucional e à fiscalização do setor de segurança (fundada em 2012 com o apoio do US-Middle East Partnership Initiative), mostram que - em 2014 - 64,4\% dos tunisianos consideravam a segurança e o contraterrorismo prioridades para as políticas do Estado, ao passo que 14,7\% se sentiam inseguros ou muito inseguros. Isso contribuiu para que os partidos políticos se mostrassem menos inclinados a empreender ativamente Reformas no Setor de Segurança, somado ao desgaste que seria demandado para enfrentar os interesses do Ministério do Interior. O desmantelamento da Direction de la sûreté de l'État, por exemplo, passou a ser amplamente criticado por minar a capacidade do Estado de conter a ameaça salafista (SAYAGHO, 2015).

A nova Constituição foi aprovada em janeiro de 2014, houve eleições legislativas em outubro e presidenciais em dezembro, marcando o fim de quatro anos de transição. A Constituição, cuja demora na promulgação revela as dificuldades dos atores políticos em assumir compromissos, dedica apenas o Artigo 17 às Forças de Segurança Interna, o qual determina que estas apenas podem ser estabelecidas pelo Estado, em conformidade com a lei e a serviço do interesse público (TUNíSIA, 2014). Não há qualquer referência à fiscalização e ao controle democrático de qualquer natureza ou à transparência dos serviços, nem redefinição dos papeis e dos objetivos do setor, embora a referência constitucional constitua o maior avanço em termos de Reforma no Setor de Segurança desde dezembro de 2011.

Béji Caïd Essebi, do partido secularista Nidaa Tournes,${ }^{18}$ venceu com 55,58\% dos votos Marzouk, candidato à reeleição. Essebi era uma figura próxima de Bourguiba, tendo servido em diversos postos, incluindo diretor da Sûreté Nationale, ministro da defesa e ministro do interior. Alguns veem na vitória do partido uma "restauração autoritária" e o "retorno ao antigo regime" (ABDERRAZAK et al., 2014). Em janeiro de 2015, um decreto fixou as estruturas das agências de inteligência, mas o texto não está disponível para consulta (TUNISIA, 2015a). ${ }^{19}$ Em novembro de 2015, um Estado de Emergência foi proclamado e sucessivamente prorrogado, estando hoje em vigor (TUNÍSIA, 2015b; TUNíSIA 2016). ${ }^{20}$

O presidente Essebi foi convidado a visitar Washington pela administração Obama. Desde 2011, os Estados Unidos aportam mais de US\$ 610 milhões em ajuda para a Tunísia. As prioridades para a política

\footnotetext{
${ }^{18}$ O partido, fundado em 2012 por Béji Caïd Essebi, se colocou rapidamente como o único desafio crível ao Ennahdha. Em seu seio, encontram-se figuras políticas próximas de Bourguiba, caciques do RCD dissolvido e também militantes de esquerda. Sua capacidade de reunir todos que se opõe ao Ennahdha se funda sob um discurso simples e federativo, que articula a temática da defesa da identidade com a preservação da modernidade (CHOUIKHA, GOBE, 2015).

${ }^{19}$ Fica claro que reside aqui, na dificuldade de acesso às legislações e na carência de fontes especializadas, a maior dificuldade no estudo da inteligência governamental. Ainda assim, Estudos em Inteligência tem se desenvolvido nos últimos anos, estabelecendo agendas próprias e métodos inovadores de investigação.

${ }^{20} \mathrm{Em}$ dezembro de 2015, surgiram boatos de que a Direction de la sûreté de l'État havia sido rearticulada e que Abderrahmen Ben Hadj Ali - que ocupou diversos postos no Ministério do Interior durante o governo Ben Ali, incluindo Diretor Geral da Guarda Presidencial - nomeado seu diretor (TUNISIE NUMERIQUE, 2015).
} 
estadunidense são a democratização, o avanço do comércio e dos investimentos, o combate ao terrorismo e a Reforma no Setor de Segurança. A administração requisitou ainda US\$ 134 milhões em ajuda para a Tunísia em 2016, mais que o dobro do requisitado em 2015, sendo em torno de $60 \%$ deste montante destinado à assistência securitária. $\mathrm{O}$ enfoque de combate ao terrorismo, no entanto, não beneficia reformas democratizantes no Ministério do Interior. A França, que é a maior fonte de investimentos e de receitas turísticas da Tunísia, teve suas relações bilaterais como o país abaladas após 2011, devido aos laços estreitos entre franceses e o regime de Ben Ali (ARIEFF, HUMUD 2015).

\section{Nigéria: instabilidades históricas e as dificuldades de promover reformas no setor de segurança entre o meio militar}

A Nigéria é um caso reconhecido e já clássico de Reforma no Setor de Segurança, tanto devido ao papel preponderante das Forças Armadas na política nacional, quanto à influência estadunidense no processo, considerando ser proveniente dos Estados Unidos grande parte das publicações sobre o tema. A Nigéria se tornou independente da Grã-Bretanha em outubro de 1960, inicialmente adotando um sistema parlamentarista e, posteriormente, em 1963, se tornando uma República Federativa. O país, à época, dividia-se em quatro regiões, que gozavam de ampla autonomia política e administrativa. Poucos anos depois, em 1966, a forte instabilidade política interna ${ }^{21}$ culminou em um golpe de Estado, que foi imediatamente seguido por um contragolpe no mesmo ano (sendo ambos golpes militares). A partir daí, o país viveu uma sucessão de governos militares que se estenderam até 1999, com um breve intervalo entre 1979 e 1983, no qual o país foi governado por um presidente civil eleito. O período militar foi marcado por diversos golpes e tentativas de golpes, e também por uma Guerra Civil, que durou três anos (1967-1970), teve altos custos (humanos e materiais) para a Nigéria e foi determinante para que houvesse um aumento expressivo no tamanho das Forças Armadas do país. ${ }^{22}$ Tal dinâmica se mostrava reveladora, assim, da existência de importantes clivagens entre os diferentes grupos da elite política nigeriana, formada essencialmente por militares (KIFORDU, 2011).

O retorno da Nigéria a um regime democrático, em 1999, foi acompanhado - assim como na Tunísia - de grandes expectativas. O país, detentor da maior população e, à época, de uma das maiores economias ${ }^{23}$ do continente africano, dava o primeiro passo para superar a longa história de regimes de exceção. Para além da restauração da democracia, uma série de desafios se apresentavam ao país, como a melhora de sua imagem internacional, a sua reestruturação econômica e o combate a elementos que haviam sido muito presentes ao longo dos governos militares, como a corrupção, o patrimonialismo e o desrespeito aos Direitos

\footnotetext{
${ }^{21}$ Como resultado dos anos de colonização e, sobretudo, das Constituições promulgadas durante o processo de independência, o país nascente foi marcado por uma forte fragmentação interna, em que as disputas políticas foram transfiguradas em disputas étnicoregionais.

${ }^{22}$ O Exército do país, que em 1967 contava com cerca de 7.000 pessoas divididas em duas Brigadas de Infantaria, vai atingir cerca de 250.000 pessoas em 1970 (AIYEDE, 2015).

${ }^{23} \mathrm{Em}$ 2014, o governo nigeriano anunciou que havia realizado uma atualização na forma de cálculo do PIB, o que resultou em um aumento de $89 \%$ no tamanho esperado da economia do país, fazendo com que a Nigéria ultrapassasse a África do Sul como maior economia do continente africano.
} 
Humanos. Nesse sentido, a Reforma do Setor de Segurança da Nigéria se apresentou como um dos elementos principais do processo de transição para o novo regime civil (AIYEDE, 2015).

A despeito do fim dos governos militares na Nigéria, a elite política do país segue contando com a participação significativa de militares. Ainda que outros grupos, como tecnocratas e professores universitários, também tenham aumentando seu peso na elite política, e que os militares estejam cada vez menos presentes em postos políticos, estes seguem tendo grande influência sobre os demais atores e sobre o sistema político nigeriano como um todo (FAYEMI; OLONISAKIN, 2008; KIFORDU, 2011; MONDAY, 2010). Outro elemento importante a respeito das elites políticas nigerianas é a sua origem geográfica. Apesar do aumento de relevância da região Sudoeste verificado a partir do retorno à democracia, em 1999, em grande medida a elite política nigeriana segue sendo predominantemente oriunda da região Norte do país (KIFORDU, 2011).

O setor de segurança da Nigéria é composto pelas Forças Armadas, ${ }^{24}$ pelo Serviço de Polícia Nigeriano, pelo Sistema de Inteligência, por Corpos Paramilitares (incluindo o serviço de imigração e as agências de inteligência específicas ${ }^{25}$ ) e pelos corpos de segurança pública e judicial (incluindo os agentes prisionais). De acordo com a Constituição da Nigéria, a responsabilidade pela Defesa (Forças Armadas) e pela segurança (Polícia e prisões) são atribuições do Governo Federal. Assim, o funcionamento das Forças Armadas é responsabilidade direta do Ministério da Defesa, e o da Polícia, do Ministério dos Assuntos Policiais (NIGERIA, 1999); a autoridade sobre as forças policiais, contudo, a despeito de sua estrutura de comando descentralizada e da existência do Ministério, é exclusiva do presidente, que também é o Comandante em Chefe das Forças Armadas (FAYEMI; OLONISAKIN, 2008). Dados do Afrobarômetro para a rodada 2011/2013 apontam para índices bastante baixos de confiança nas forças de segurança. Enquanto 15,5\% dos nigerianos afirmavam confiar muito no Exército, apenas 4\% afirmavam confiar da mesma maneira na Polícia.

Em 1999, quando Olusegun Obasanjo chegou ao poder na Nigéria pela via eleitoral, teve início um amplo processo de Reforma do Setor de Segurança no país. Nesse processo, o governo nigeriano buscou o apoio de agências externas, ${ }^{26}$ como a empresa Military Professional Resources Incorporated (MPRI), o British Defence Advisory Team e o programa de Treinamento e Educação Militar Internacional do governo dos Estados Unidos ${ }^{27}$ (AIYEDE, 2015). As reformas propostas tinham como objetivos garantir o controle governamental sobre os militares, bem como a supremacia de oficiais de Estado eleitos sobre oficiais indicados, em todos os níveis; de um civil no comando do Ministério da Defesa e de outros serviços estratégicos; da prerrogativa das autoridades civis na definição dos objetivos políticos e estratégicos das operações militares; da aplicação de princípios civis em todas as investigações e julgamentos militares; e do

\footnotetext{
${ }^{24}$ Segundo o Military Balance de 2014, produzido pelo International Institute of Strategic Studies, o Exército nigeriano possui um efetivo de 60.000, a Força Aérea, 9.000 e a Marinha, 15.000 pessoas.

${ }^{25}$ A Nigéria possui três agências de inteligência paramilitares, a Nigerian Immigration Service (NIS), a Nigerian Prision Sercice (NPS) e a Nigerian Security and Civil Defence Corps (NSCDC) - esta última atuando em conjunto com a Polícia nigeriana, principalmente na defesa de oleodutos.

${ }^{26}$ Tal iniciativa gerou resistências por parte dos militares (AIYEDE, 2015).

${ }^{27}$ International Military Education and Training programme.
} 
direito da Suprema Corte (civil) para rever ações e decisões dos juízes militares (FAYEMI; OLONISAKIN, 2008).

Nesse sentido, algumas das primeiras medidas adotadas foram a aposentadoria compulsória de aproximadamente 100 Generais e outros oficiais que ocupavam cargos políticos; o anúncio de uma iniciativa de combate à corrupção, que culminou no cancelamento imediato de diversos contratos que haviam sido estabelecidos durante o regime militar; e o estabelecimento de uma comissão judicial para investigar violações de Direitos Humanos cometidas pelos militares. Além disso, o governo Obasanjo também estabeleceu a supervisão pelo Legislativo do orçamento de Defesa, exigindo o escrutínio da Assembleia Nacional para a sua aprovação e lhe concedendo poder de controle e fiscalização, além de ter sido responsável pela formulação da Política de Defesa Nacional, ${ }^{28}$ em 2006 (AIYEDE, 2015).

Outra medida adotada pelo governo Obasanjo foi uma reestruturação das Forças Policiais da Nigéria. Com cerca de 120.000 pessoas, a polícia nigeriana apresentava um efetivo sensivelmente abaixo do recomendado pelas Nações Unidas, ${ }^{29}$ o que criava uma demanda de participação dos militares em funções de polícia no país e teria sido um dos elementos responsáveis pelo surgimento de grupos de Milícias (INYANG; ABRAHAM, 2013). Tal reestruturação, contudo, resumiu-se a um expressivo aumento do efetivo, que atingiu o número de 360.000 pessoas, agravando ainda mais problemas anteriormente existentes, como a falta de recursos para treinamento, transporte e logística, entre outros. Ainda que as mudanças tenham permitido ao governo diminuir a participação dos militares nas patrulhas que eram realizadas em conjunto com a polícia, não houve uma reconsideração das estratégias de ação adotadas pelas forças policiais nigerianas, que seguiram investindo pouco em ações preventivas, adotando uma postura mais combativa (FAYEMI; OLONISAKIN, 2008).

Paralelamente às reformas promovidas pelo governo, as próprias lideranças do Exército nigeriano deram início a um processo de reforma interno. Além da formação de um Comitê de Gestão de Mudanças, em 2004, foi lançado um documento identificando as necessidades de treinamento, equipamento e de estrutura do Exército nigeriano, intitulado A Framework for the Transformation of the Nigerian Army in the Next Decade, e foi estabelecido o Escritório de Transformação do Exército Nigeriano (Office of Nigerian Army Transformation), em 2006, com a responsabilidade de monitorar e avaliar o processo de transformação, bem como conceber, desenvolver e implementar projetos de curto, médio e longo prazo para a mudança do Exército. No mesmo ano, foi estabelecido um o Comitê de Transformação das Forças Armadas junto ao Ministério da Defesa, com o objetivo de expandir as mudanças para as demais Forças. Como resultado, em 2008 foram produzidos um documento de Estratégia Militar Nacional, dois documentos de doutrina conjunta para as Forças Armadas e uma proposta de estrutura para a gestão superior da Defesa (AIYEDE, 2012).

\footnotetext{
${ }^{28}$ Baseado em uma perspectiva de segurança humana, o documento, que se tornou o principal guia para a reforma militar da Nigéria, prevê a contribuição militar para questões relacionadas a operações de inteligência e logística, e determina uma maior proeminência dos civis na formulação de políticas e nos gastos com defesa (AIYEDE, 2012).

${ }^{29}$ A proporção ideal estabelecida pela ONU é de um policial para 400 cidadãos; a Nigéria apresentava uma proporção de aproximadamente 1:1.000 (FAYEMI; OLONISAKIN, 2008).
} 
O processo de Reforma do Setor de Segurança da Nigéria, contudo, perdeu força a partir do final do segundo mandato de Obasanjo, especialmente por conta da ênfase excessiva dada pelo então presidente em sua proposta de alterar a Constituição de forma a permitir um terceiro mandato, o que retirou grande parte do apoio que possuía na Assembleia Nacional. O governo seguinte, de Umaru Musa Yar'Adua, iniciado em 2007, estabeleceu a Reforma do Setor de Segurança como uma de suas prioridades, mas tampouco conseguiu avançar no projeto, em grande medida por conta da situação de saúde do presidente, que passou parte do mandato afastado do cargo, e faleceu antes de encerrá-lo. Goodluck Johnatan, que assumiu como interino após o falecimento de Yar'Adua em 2010, sendo depois eleito presidente, também não promoveu avanços significativos para o setor. Ainda que durante o seu mandato tenha havido grande mobilidade nas lideranças militares, demonstrando um efetivo controle civil, também houve um aumento expressivo no orçamento de defesa, que passou de US\$ 625 milhões, em 2010, para US\$ 6 bilhões, em 2011 e US\$6,25 bilhões em 2012, 2013 e 2014 (AIYEDE, 2015).

Em certa medida, o aumento do orçamento da Defesa esteve ligado à intensificação de algumas ameaças securitárias e ao seu combate na Nigéria. Além dos movimentos insurgentes existentes no Delta do rio Níger, a partir de 2010 houve uma intensificação nos ataques realizados pelo Boko Haram $^{30}$ no país. O Movimento pela Emancipação do Delta do Níger (MEND) surgiu em 2005, e concentrou sua atuação na

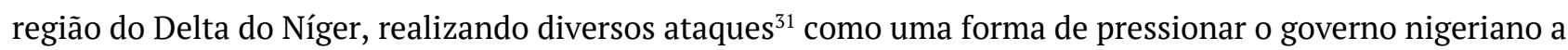
atender suas reivindicações. Não tendo conseguido conter as ações do MEND, o governo nigeriano propôs, em 2009, um plano que previa a anistia de todos os membros do movimento que entregassem as armas, além de atender algumas das demandas do grupo (GHOSH, 2013). O plano proposto pelo governo foi razoavelmente bem-sucedido, com o MEND diminuindo consideravelmente seus ataques no Delta do Níger a partir de 2011 (BEVAN et al, 2013).

O Boko Haram, por sua vez, surgiu no início dos anos 2000, e ao longo da década intensificou sua atuação, sendo fortemente combatido pelas forças de segurança nigerianas até 2009, quando parte significativa do grupo foi desmantelada. ${ }^{32}$ Após mais de um ano de inatividade, o Boko Haram retomou seus ataques, expandindo sua área de atuação e adotando um perfil mais violento, ${ }^{33}$ realizando inclusive um ataque a bomba à sede da ONU em Abuja, em 2011 (START, 2014). Diante da situação, o governo nigeriano intensificou as operações de combate ao grupo, tendo relativo sucesso em reduzir seus ataques, especialmente entre 2012 e o início de 2013, quando eles ganharam força novamente (BLANCHARD, 2014).

Em 2015, foram realizadas eleições gerais na Nigéria. Nelas, o candidato de oposição, ${ }^{34}$ Muhammadu Buhari, que havia sido um dos governantes militares do país, entre 1983 e 1985, foi eleito presidente com

\footnotetext{
${ }^{30}$ Grupo fundamentalista islâmico que defende a implementação e uma interpretação estrita das leis islâmicas (Shari'a).

${ }^{31}$ Os ataques iam desde o sequestro de funcionários de empresas produtoras de petróleo até a destruição de gasodutos, oleodutos e plataformas de exploração, além de roubos frequentes de quantidades significativas de petróleo.

32 As forças nigerianas lançaram uma ofensiva ao grupo que resultou na morte de cerca de setecentas pessoas suspeitas de envolvimento com as ações do Boko Haram - entre elas o seu líder, Mohammed Yusuf, morto enquanto estava sob custodia policial (PLOCH, 2013).

${ }^{33}$ Inicialmente os ataques do Boko Haram se limitavam às forças policiais. Nesse segundo momento, o grupo também passou a visar mesquitas, igrejas e civis - nigerianos e estrangeiros (START, 2014).

${ }^{34}$ Buhari concorreu pelo partido All Progressive Congress (APC), uma combinação de três partidos oriundos das diferentes regiões nigerianas.
} 
53,9\% dos votos, derrotando o então presidente, Goodluck Johnatan. A concretização das eleições sem grandes distúrbios ou intervenções dos militares foi amplamente comemorada, especialmente por ter sido a primeira vez que um partido de oposição conseguiu vencer o pleito (FAKUDE, 2015). Pouco depois de assumir o governo, Buhari substituiu os chefes dos serviços militares que haviam sido indicados por Jonathan - alguns dos quais eram suspeitos de crimes internacionais - e estabeleceu um comitê de investigação do setor de segurança, que culminou na descoberta da existência de diversos contratos falsos e, consequentemente, na prisão de diversos envolvidos - entre eles o Conselheiro de Segurança Nacional entre 2012 e 2015. Ademais, Buhari prometeu investigar crimes de guerra e possíveis crimes contra a humanidade cometidos pelas Forças Armadas nigerianas em seu combate ao Boko Haram entre 2011 e 2015, porém não foram tomadas ações concretas nesse sentido ${ }^{35}$ (AI, 2016).

O presidente Muhammadu Buhari, pouco depois de assumir o cargo, realizou uma visita oficial aos Estados Unidos, na qual assuntos como o combate ao Boko Haram e a cooperação em Defesa foram discutidas. Desde 2011, os Estados Unidos aportam entre US\$ 600 e US\$ 700 milhões anuais em ajuda para a Nigéria, sendo o país um dos principais receptores da ajuda dos Estados Unidos no continente. As prioridades para a política estadunidense são o desenvolvimento da democracia nigeriana e a redução da extrema pobreza no país, bem como a profissionalização e a reforma dos serviços de segurança nigerianos. Nesse sentido, o Departamento de Estado americano tem focado sua assistência em segurança no treinamento especializado para aplicação de leis, na profissionalização militar, no apoio e treinamento para missões de paz e na segurança fronteiriça e marítima (BLANCHARD; HUSTED, 2016).

\section{Considerações Finais}

Tanto na Tunísia quanto na Nigéria, o estabelecimento de regimes de transição foi acompanhado de entusiasmados esforços iniciais de reestruturação de seus setores de segurança. Em ambos os países, no entanto, a implementação destes ambiciosos projetos, formulados desde o topo das hierarquias políticas, foi titubeante, resultou em meras reformas cosméticas (demissões de servidores, mudanças nos nomes de instituições, sem alterar seus mandatos, etc.), e/ou foi gradualmente abandonada. Em nenhum caso houve de fato - o prosseguimento de planos bem estruturados, coerentes e verdadeiramente interessados em controle civil democrático. Nos dois países, as causas deste fenômeno se mostraram semelhantes, confirmando a hipótese de pesquisa inicialmente perseguida.

Em primeiro lugar, tanto as elites que serviam de sustentáculo ao regime anterior (no caso da Tunísia, reunidas sob o Ministério do Interior e, no caso da Nigéria, sob o Ministério da Defesa) se mostraram especialmente resistentes em abandonar seu papel político preponderante. Com efeito, os novos governantes eleitos buscaram preservar sua autoridade ao postergarem estas reformas: ora dando ênfase a projetos próprios de poder, ora se preservando do desgaste a ser gerado pela ameaça aos interesses destas elites previamente estabelecidas. Em segundo lugar, a escalada de ameaças securitárias minou os esforços por Reforma no Setor de Segurança em ambos os países, uma vez que o combate ao terrorismo e ao tráfico

\footnotetext{
${ }^{35}$ Além disso, Segundo a Anistia Internacional, as execuções extrajudiciais, pelos militares, de suspeitos de serem membros do Boko Haram seguem ocorrendo (AI, 2016).
} 
demandava Serviços de Inteligência estruturados e Forças Armadas e Policiais coesas. Logicamente, esta constatação relaciona-se à primeira exposta, uma vez que o discurso securitário pode ser instrumentalizado pelos interesses destas instituições, os quais - logicamente - não são monolíticos.

Sobre RSS, apesar da proliferação de estudos a respeito, desde a metade dos anos 1990, o conceito não se estabeleceu ainda como uma agenda política universalmente aceita, justamente devido a sua normatividade e ao foco em um tipo de reforma muito específica, qual seja, aquela de caráter democratizante, sob os princípios da "boa governança" e consoante com a segurança humana. Nos dois casos aqui trabalhados, os Estados Unidos se colocaram como um ator importante e auto interessado, prestando assistência a programas de treinamento e de assistência técnica sob condicionalidades, com uma abordagem problem-driven e não pautada sobre o contexto e as peculiaridades nacionais.

Em continuação ao estudo aqui apresentado, seria possível o alargamento do número de estudos de caso, com o objetivo de dar-lhe maior robustez, incluindo outros países norte-africanos que passam também por processos de Reforma no Setor de Segurança a partir de regimes autoritários, tal como o Egito e a Líbia, e outros países subsaarianos, tal como o Zimbábue. A título de contribuição aos estudos na área, sublinha-se a importância do mapeamento das elites e de suas relações com as instituições e burocracias analisadas. Igualmente, a questão do ambiente securitário jamais pode ser perdida de vista, não apenas por ter implicações diretas sobre as atividades do setor de segurança, mas porque, não raramente, o espectro da insegurança serve de justificativa a regimes de segurança.

\section{REFERÊNCIAS}

ABDERRAZAK, Ben et al. En Tunisie, le retour de l'ancien régime n'est pas une rumeur. Libération. Paris, p. 1-2. 21 nov. 2014. Disponível em: <http://www.liberation.fr/debats/2014/11/21/en-tunisie-leretour-de-l-ancien-regime-n-est-pas-une-rumeur_1147107>. Acesso em: 26 maio 2016.

AI, Amnesty International. Amnesty International Report 2015/2016: the state of the world's human rights. London: Amnesty International, 2016.

AIYEDE, E. Remi, Parliament, Civil Society and Military Reform in Nigeria. In: RÛLAND, Jürgen; MANEA, Maria-Gabriela; BORN, Hans (Eds.). The Politics of Military Reform: Experiences from Indonesia and Nigeria. Berlin: Springer, 2012, cap.8, p.161-184.

AIYEDE, E. Remi. Democratic Security Sector Governance and Military Reform in Nigeria. In: BRYDEN, A.; CHAPPUIS, F. (Eds.). Learning from West African Experiences in Security Sector Governance. London: Ubiquity Press, 2015, cap. 6, p.97-116.

ALEXANDER, Christopher. Tunisia. In: GASIOROWSKI, Mark (Ed.). The Government and Politics of the Middle East and North Africa. Boulder: Westview Press, 2014. p. 475-500.

ARIEFF, Alexis; HUMUD, Carla E.. Political Transition in Tunisia. Washington: Congressional Research Service, 2015. Disponível em: <https://www.fas.org/sgp/crs/row/RS21666.pdf>. Acesso em: 25 maio 2016.

AYARI, Michaël Béchir; MERONE, Fabio. Ansar al-Sharia: une institutionnalisation à la croisée des chemins. In: CAMAU, Michel; VAIREL, Frédéric (Org.). Soulèvements et recompositions politiques dans le monde arabe. Montréal: Les Presses de L'université de Montréal, 2014. p. 414-428. 
BENDIX, Daniel; STANLEY, Ruth. Security Sector Reform in Africa: The Promise and the Practice of a New Donor Approach.Occasional. Paper Series, Durban, v. 3, n. 2, p.9-32, jun. 2008. Disponível em: <http://www.operationspaix.net/DATA/DOCUMENT/5405 v Security_Sector_Reform_in_Africa_T he_Promise_and_the_Practice_of_a_New_Donor_Approach.pdf>. Acesso em: 15 maio 2016.

BEVAN, James et al. Transnational Organized Crime in West Africa: A Threat Assessment. Viena: United Nations Office on Drugs and Crime (UNODC), 2013.

BLANCHARD, Lauren P. Nigeria's Boko Haram: Frequently Asked Questions. CRS Report, Congressional Research Service, 2014, 24p. Disponível em: <http://fas.org/sgp/crs/row/R43558.pdf>. Acesso em: 15 jun. 2014.

BLANCHARD, Lauren P.; HUSTED, Tomas F. Nigeria: Current Issues and U.S. Policy. CRS Report, Congressional Research Service, 2013, 26p. Disponível em <https://www.fas.org/sgp/crs/row/RL33964.pdf>. Acesso em 01 jun. 2016.

BRUNEAU, Thomas C.; MATEI, Florina Cristiana (cris). Towards a New Conceptualization of Democratization and Civil-Military Relations. Democratization, [s.l.], v. 15, n. 5, p.909-929, dez. 2008

CAMAU, Michel. La Tunisie. Paris: Presses Univrsitaires de France, 1989.

CEPIK, Marco. Sistemas Nacionais de Inteligência: Origens, Lógica de expansão e Configuração Atual. Revista de Ciências Sociais, Rio de Janeiro, v. 46, n.1, 2003. p.75-127.

CHOUIKHA, Larbi; GOBE, Éric. Histoire de la Tunisie depuis l'independance. Paris: La Découverte, 2015.

CROISSANT, Aurel; KUEHN, David. The Military's Role in Politics. In: GANDHI, Jennifer; RUIZ-RUFINO, Rubén (Ed.).Routledge Handbook of Comparative Political Institutions. Nova York: Routledge, 2015. p. 258-276.

DUVERGER, Maurice. Sociologie Politique. Paris: Presses Univrsitaires de France, 1967.

FAKUDE, Thembisa. New Era in Nigerian Politics. Al Jazeera Centre for Studies Report. 2015, 6p. Disponível em

http://studies.aljazeera.net/mritems/Documents/2015/4/15/20154157123366580New\%20Era\%20in \%20Nigerian\%20Politics.pdf>. Acesso em 01 jun. 2016.

FAYEMI, J. 'Kayode; OLONISAKIN, ‘Funmi. Nigeria. In: BRYDEN, Alan; N’DIAYE, Boubacar; OLONISAKIN, 'Funmi (Eds.). Challenges of Security Sector Governance in West Africa. Geneva: Geneva Centre for the Democratic Control of Armed Forces, 2008, cap. 14, p.243-267.

FERGUSON, Chris; ISIMA, Joffrey O (Ed.). Providing Security for People: Enhacing Security rhrough Police, Justice and Intelligence Reform. Shrivenham: Gfn-ssr, 2004.

GHOSH, P.K. Waiting to Explode: Piracy in the Gulf of Guinea. ORS Occasional Paper No46. New Delhi: Observer Research Foundation, 2013, 38p.

HÄNGGI, Heiner. Conceptualising Security Sector Reform and Reconstruction. In: BRYDEN, Alan; HÄNGGI, Heiner (Ed.).Reform and Reconstruction of the Security Sector. [s.I.]: Dcaf Yearly Books, 2004. p. 3-20.

HANLON, Querine. Security Sector Reform in Tunisia: A Year after the Jasmine Revolution. Washington: The U.s. Institute Of Peace Security Sector Governance Center Is Engaged In A Funded Study Of The Prospects For Security Sector Reform In North Africa., 2012. Disponível em: <https://www.usip.org/sites/default/files/SR304.pdf>. Acesso em: 24 maio 2016. 
HILL, Alice. Learning the Hard Way: Implementing SSR in Africa's Post-Authoritarian States. In: SEDRA, Mark (Ed.). The Future of Security Sector Reform. Ontario: The Centre For International Governance Innovation, 2010. p. 177-191.

ICG, International Crisis Group. Tunisie: Lutter contre l'impunité, restaurer la sécurité. 123. ed. [s.i]: [s.i], 2012. Disponível em: <http://www.crisisgroup.org/ /media/Files/Middle East North Africa/North Africa/123-tunisie-lutter-contre-1-impunite-restaurer-la-securite>. Acesso em: 21 maio 2016.

IISS, International Institute Of Strategic Studies. The Military Balance 2010: The annual assessment of global military capabilities and defence economics. [s.i]: [s.i], 2010.

IISS, International Institute Of Strategic Studies. The Military Balance 2014: The annual assessment of global military capabilities and defence economics. [s.i]: [s.i], 2014.

INYANG, John D.; ABRAHAM, Ubong E. Policing Nigeria: a case for partnership between formal and informal police institutions. Merit Research Journal of Art, Social Science and Humanities, [S.1.], v.1, n.4, 2013, p.53-58.

JEBNOUN, Noureddine. In the shadow of power: civil-military relations and the Tunisian popular uprising. The Journal Of North African Studies, [s.1.], v. 19, n. 3, p.296-316, 3 mar. 2014a.

JEBNOUN, Noureddine. Security \& the Tunisian Constitution. Middle East Studies. [s.i], p. 1-3. fev. 2014b. Disponível em: <http://www.mei.edu/content/security-tunisian-constitution>. Acesso em: 22 maio 2016.

KIFORDU, Henry A. Politica Elite Composition and Democracy in Nigeria. The Open Area Studies Journal, Beijing, v.4, Special Edition, 2011, p.16-31.

LUTTERBECK, Derek. Tunisia after Ben Ali: Retooling the tools of oppression?. [s.I.]: Norwegian Peacebuilding Resource Center, 2013. Disponível em: $<$ http://www.peacebuilding.no/Regions/Middle-East-and-North-Africa/Publications/Tunisiaafter-Ben-Ali-retooling-the-tools-of-oppression>. Acesso em: 23 maio 2016.

MAHFOUDH, Haykel Ben. Security Sector Reform in Tunisia: Three Years into the Democratic Transition. [s.i]: Arab Reform Institute, 2014. Disponível em: <http://www.arab-reform.net/security-sectorreform-tunisia-three-years-democratic-transition>. Acesso em: 23 maio 2016.

MONDAY, Omodia S. Elite Recruitment and Political Stability in the Nigerian Fourth Republic. Journal of Social Sciences, Haryana, v.24, n.2, 2010, p.129-133.

NIGERIA (1999). Lei ${ }^{0}$ [s.I], Constitution of the Federal Republic of Nigeria, 1999. Disponível em: $<$ http://www.nigeria-law.org/ConstitutionOfTheFederalRepublicOfNigeria.htm>. Aceso em 06 jun. 2016.

NUMÉRIQUE, Tunisie. Tunisie- Qui est A. Hadj Ali?: Nouveau directeur de la sûreté nationale. Tunisie Numérique. Tunis, p. 1-1. 02 dez. 2015. Disponível em: $<$ http://www.tunisienumerique.com/tunisie-qui-est-a-hadj-ali-nouveau-directeur-de-la-suretenationale/274570>. Acesso em: 25 maio 2016.

OCDE, Organização Para A Cooperação e Desenvolvimento Econômico. OECD DAC Handbook on Security System Reform: Supporting security and justice. [s.I.]: Oecd, 2008.

ONU, Organização das Nações Unidas; COUNCIL, Human Rights. National report submitted in accordance with paragraph 5 of the annex to Human Rights Council resolution 16/21: Tunisia. Genebra: [s.i], 2012. Disponível em: <http://ap.ohchr.org/documents/alldocs.aspx?doc_id=20960>. Acesso em: 23 maio 2016.

PACHON, Alejandro. Loyalty and Defection: Misunderstanding Civil-Military Relations in Tunisia During the 'Arab Spring'.Journal Of Strategic Studies, [s.1.], v. 37, n. 4, p.508-531, 16 abr. 2014. 
PERITO, Robert M.. Security Sector Reform in North Africa: Why It's Not Happening. Security Sector Reform Resource Center. [s.i], p. 1-5. 07 jan. 2015. Disponível em: <http://www.ssrresourcecentre.org/2015/01/07/security-sector-reform-in-north-africa-why-itsnot-happening/>. Acesso em: 01 jun. 2015.

QUINLIVAN, James T.. Coup-proofing: Its Practice and Consequences in the Middle East. International Security, [s.i], v. 24, n. 2, p.131-165, out. 1999.

SAYIGHO, Yezid. Missed Opportunity: The Politics of Police Reform in Egypt and Tunisia. Washington: Carnegie Endowment For International Peace, 2015.

SHORT, Clare. Security Sector Reform and the Elimination of Poverty (Discurso). Londres: Centre For Defence Studies, King's College, 1999. Disponível em: <http://www.clareshort.co.uk/speeches/DFID/9 March 1999.pdf>. Acesso em: 05 maio 2016.

START, National consortium for the study of Terrorism and responses to Terrorism. Boko Haram Recent Attacks. START Background Report, University of Maryland, 2014, 8p. Disponível em: <http://www.start.umd.edu/pubs/STARTBackgroundReport_BokoHaramRecentAttacks_May2014_0 .pdf>. Acesso em: 05 jun. 2014.

STEPAN, Alfred. Tunisia's Transition and the Twin Tolerations. Journal Of Democracy, Baltimore, v. 23, n. 2, p.89-103, abr. 2012.

STONE, Russel A.. Tunisia: A single party system holds change in Abeyance. In: ZARTMAN, William et al. Political Elites in Arab North Africa. Nova York: Longman, 1982. p. 144-176.

TUNÍSIA (1975). Decreto nº 343, de 30 de maio de 1975. Organisation Du Ministère de L’intérieur. Tunis.

TUNÍSIA (1982). Lei nº 70, de 06 de agosto de 1982. Statut Général Des Forces de Sécurité Intérieure. Tunis,

TUNÍSIA (2014). Lei n ${ }^{\circ}$ [s.I.], de 27 de janeiro de 2014. Constitution de La République Tunisienne. Tunis.

TUNÍSIA (2015a). Decreto $\mathrm{n}^{\circ}$ 31, de 19 de janeiro de 2015. Modification Du Décret $\mathbf{N}^{\circ}$ 2007-246 Du 15 Août 2007, Fixant Les Structures Des Forces de Sûreté Intérieure Au Ministère de L’intérieur Et Du Développement Local. Tunis.

TUNÍSIA (2015b). Decreto $\mathrm{n}^{\circ}$ 251, de 24 de novembro de 2015. Proclamant L'état D'urgence. Tunis.

TUNÍSIA (2016). Decreto $n^{\circ}$ 31, de 22 de março de 2016. Prorogation de L'état D’urgence. Tunis.

WULF, Herbert. Security-Sector Reform in Developing and Transitional Countries. Berlim: The Berghof Center For Constructive Conflict Management, 2004. 


\title{
RESUMO
}

O objetivo deste artigo é analisar duas tentativas de RSS em países do continente africano que sofrem transições políticas a partir de regimes autoritários: Nigéria, onde os esforços por reforma iniciaram-se após 1999, com a eleição de Olusegun Obasanjo, e Tunísia, dentro do quadro posterior às manifestações que resultaram na queda de Zine Ben Ali, em 2011. Os esforços deste artigo se concentrarão em duas frentes. Os processos de RSS serão analisados naquilo que se refere a (i) quais os contextos imediatamente anteriores à proposição das reformas, buscando identificar os principais atores políticos; (ii) quais as políticas de reforma propostas; (iii) quais os resultados observáveis; (iv) quais os atores externos (doadores) envolvidos. Concomitantemente, deve-se analisar o ambiente securitário no momento de proposição e de implementação. A hipótese de trabalho é que nestes dois países, onde as forças de segurança desempenharam e desempenham um papel político fundamental, níveis de resistência a Reformas no Setor de Segurança se darão devido à manutenção da influência destes atores e - especialmente - a imperativos securitários. Apesar da visão holística adotada pela Organização para a Cooperação e Desenvolvimento Econômico relativa àquilo que compõe uma comunidade de segurança (OCDE, 2007), este artigo se propõe a analisar apenas as reformas em nível de Forças Armadas, polícias, serviços de inteligência e órgãos responsáveis pelo monitoramento destas instituições. Ademais, serão buscadas conclusões preliminares, uma vez que os processos ainda estão em andamento.

Palavras-chave: Reforma no Setor de Segurança, Pós-autoritarismo, Nigéria, Tunísia.

\begin{abstract}
The main goal of this paper is to analyze two SSR attempts in African countries that underwent political transitions from authoritarian political regimes: Nigeria, where the reform efforts began in 1999, after the election of Olusegun Obasanjo, and Tunisia, after the demonstrations that resulted in the fall of Zine Ben Ali in 2011. The efforts of this article will focus on two fronts. The SSR processes will be analyzed in what refers to (i) the contexts immediately preceding the proposition of the reforms, seeking to identify the main political actors involved; (ii) the proposed policies reforms; (iii) the observable results; (iv) the external actors (donors) involved. Concurrently, the security context during the proposition and implementation of the reforms should be analyzed. The paper's hypothesis is that in these two countries, where the security forces played and still play a fundamental political role, levels of resistance to Security Sector Reforms will occur due to the maintenance of these actors' influence and especially to security imperatives. Despite the holistic vision of the Organization for Economic Cooperation and Development (OECD, 2007) about the composition of a security community, this paper seeks to analyze only reforms at the Armed Forces, police, intelligence services and the services responsible for the monitoring of these institutions. In addition, preliminary conclusions will be sought since the processes are still in progress.
\end{abstract}

Key-words: Security Sector Reforms; Post-authoritarianism; Nigeria; Tunisia. 